
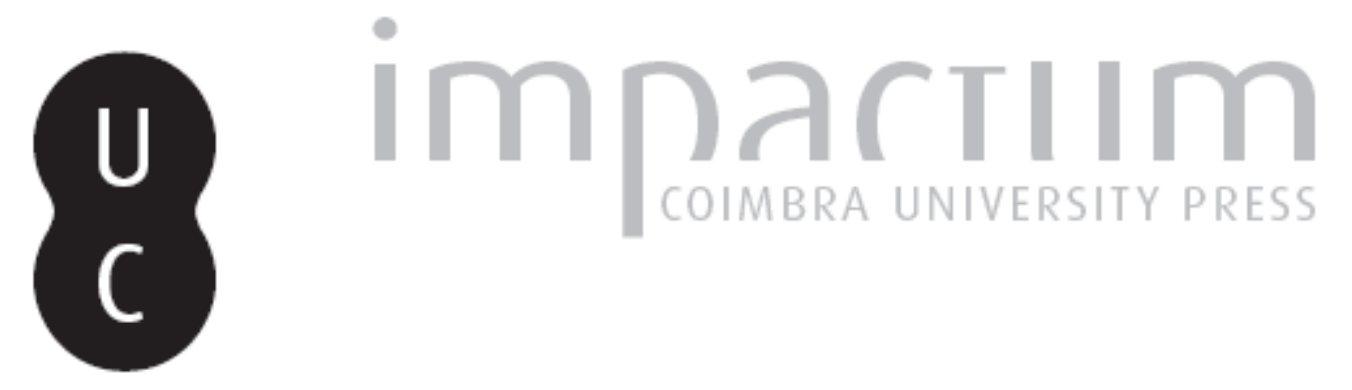

\title{
[Recensão a] BERYL RAWSON, ed., A Companion to Families in the Greek and Roman Worlds
}

\author{
Autor(es): $\quad$ Rodrigues, Nuno Simões \\ Publicado por: Centro de História da Universidade de Lisboa \\ URL \\ persistente: \\ URI:http://hdl.handle.net/10316.2/35021 \\ DOI: \\ DOI:http://dx.doi.org/10.14195/0871-9527_23_26
}

Accessed : $\quad$ 26-Apr-2023 15:23:23

A navegação consulta e descarregamento dos títulos inseridos nas Bibliotecas Digitais UC Digitalis, UC Pombalina e UC Impactum, pressupõem a aceitação plena e sem reservas dos Termos e Condições de Uso destas Bibliotecas Digitais, disponíveis em https://digitalis.uc.pt/pt-pt/termos.

Conforme exposto nos referidos Termos e Condições de Uso, o descarregamento de títulos de acesso restrito requer uma licença válida de autorização devendo o utilizador aceder ao(s) documento(s) a partir de um endereço de IP da instituição detentora da supramencionada licença.

Ao utilizador é apenas permitido o descarregamento para uso pessoal, pelo que o emprego do(s) título(s) descarregado(s) para outro fim, designadamente comercial, carece de autorização do respetivo autor ou editor da obra.

Na medida em que todas as obras da UC Digitalis se encontram protegidas pelo Código do Direito de Autor e Direitos Conexos e demais legislação aplicável, toda a cópia, parcial ou total, deste documento, nos casos em que é legalmente admitida, deverá conter ou fazer-se acompanhar por este aviso.

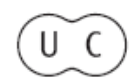



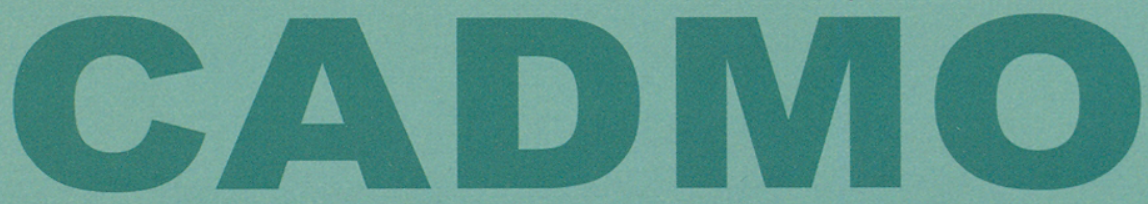

Revista de História Antiga

\author{
Centro de História \\ da Universidade de Lisboa
}

\title{
23
}

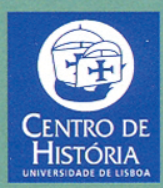

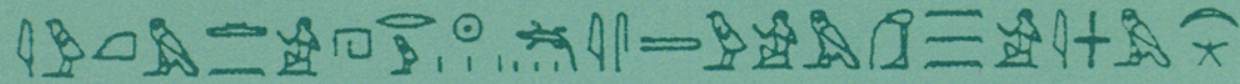

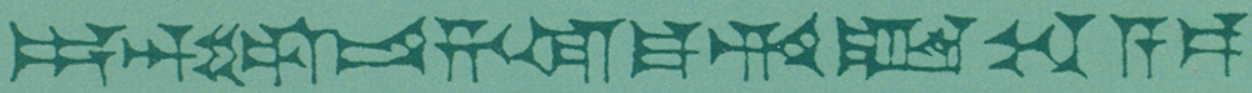
MHNIN AEI $\triangle \mathrm{E} \Theta \mathrm{EA}$ ПH$\Lambda \mathrm{HIA} \triangle \mathrm{E} \Omega$ 
quais destacamos E. Bartman (escultura), E. D. Carney (dinastias macedónicas), E. D'Ambra (mulher romana), J. P. Hallet (sexualidade e família), E. A. Hemelrijk (mulheres romanas eruditas), M. M. Henry (prostituição), R. S. Kraemer (judaísmo e cristianismo no feminino), B. Levick (Júlio-Cláudios), J. Neils (arte grega) e G. Shepherd (criança grega).

O livro inclui extensas bibliografias (em que todavia predominam os títulos anglo-saxónicos), organizadas de acordo com os vários temas tratados, mapas, figuras, respectivas legendas, índices onomásticos e temáticos. Uma obra fundamental para todos os que se interessam pelo tema.

\section{Nuno Simões Rodrigues}

BERYL RAWSON, ed., A Companion to Families in the Greek and Roman Worlds. Blackwell Companions to the Ancient World, Oxford: Blackwell Publishing Ltd., 2011, 643 pp. ISBN 978-1-4051-8767-1.

Seguindo o modelo da «Blackwell Companions», este livro de apoio ao estudo da família no mundo greco-romano apresenta o «estado da arte» do problema e está dividido em cinco partes, sendo que em cada uma delas se pretende abordar as áreas tidas como fundamentais para a problemática em questão.

Assim, a parte I («Houses and Households», pp. 13-213) centra-se no problema da casa (oikos/domus) e do agregado familiar, sendo apresentados contributos em torno do espaço doméstico, da estruturação do casamento (monogâmico e poligínico) e da forma como esta determina o funcionamento da família dentro da sociedade em que se insere, das dinastias associadas ao poder no caso das sociedades monárquicas (e.g. Macedónia), das alteridades familiares e da constituição das casas/famílias, incluindo os servos e os bens.

A parte II («Kinship, Marriage, Parents, and Children», pp. 215-330) inclui estudos acerca das relações de sangue no seio da família, mas também da problemática da sexualidade, da bastardia e do casamento. É todavia na parte III («The Legal Side», pp. 331-392) que encontramos excelentes sínteses sobre as questões legais (e.g. estudo de Cantarella sobre a lei e a família na Grécia), nos quais se abordam temas que vão do património e do direito sucessório à adopção, quer na Grécia quer em Roma.

A parte IV («City and Country», pp. 393-444) estuda, como anuncia, as relações da família com as organizações políticas e estruturas geográficas. Não podemos deixar de assinalar o excelente trocadilho escolhido por C. Johanson para entitular o seu texto, "A Walk with the Dead». A V e última parte, 
«Ritual, Commemoration, Values» (pp. 445-563), entra a fundo nas questões da religiosidade e na forma como esta determina e é determinada pela família, ao mesmo tempo que aborda a problemática das suas representações.

Em síntese, confirmando a qualidade a que a Blackwell já nos habituou, este «Companion» é mais um excelente instrumento de trabalho para os estudiosos da Antiguidade Clássica e deve marcar presença em todas as boas bibliotecas dedicadas ao assunto. A obra reúne os contributos de 32 autores, alguns especialistas reconhecidos nos seus campos de estudo, dos quais

destacamos E. Cantarella (direito greco-romano), S. Dixon (mulher romana), J. F. Gardner (mulher e direito em Roma), M. Golden (criança grega), C. Laes (criança e jovens em Roma), D. Noy (estrangeiros e alteridade em Roma), D. Ogden (religião e mitologia grega, Alexandre e período macedónico) e C. Osiek (judaísmo e cristianismo antigos).

O livro inclui uma extensa bibliografia, glossário, mapas, figuras, respectivas legendas e índice misto.

\section{Nuno Simões Rodrigues}

RADCLIFFE G. EDMONDS III, Redefining Ancient Orphism. A Study in Greek Religion, Cambridge: Cambridge University Press, 2013, 451 pp. ISBN 9781-107-03821-9 (£70.00, US\$110.00)

Este livro deverá constituir-se dos melhores estudos alguma vez feitos sobre o orfismo. Nele, encontramos a recolha, a síntese e a reavaliação da informação coligida e tratada tanto pelos primeiros autores a dedicarem-se ao estudo dos órficos e da religião órfica, como pelos já "clássicos do orfismo" (e.g. Guthrie e Bernabé - aliás, abundantemente citado na bibliografia (23 títulos) e ao longo do texto, o que por si só expressa a qualidade do livro que temos em mãos, visto tratar-se de um autor anglófono que demonstra o conhecimento que tem dos seus pares, falantes de outras línguas, como o castelhano!).

Orfeu e o orfismo são elementos centrais na cultura grega, tanto quanto o facto de se identificarem com aspectos mitológicos, por um lado, mas também com um sistema religioso hoje mal conhecido mas que sabemos integrar-se nas religiões ditas de mistérios. Entre vários outros aspectos, o orfismo valorizava a culpabilidade humana (quase um pecado original relacionado com a morte de Dioniso) e a punição do mal numa vida além-túmulo e a posterior transmigração cíclica das almas para uma existência superior, como acontecia também no pitagorismo. O objectivo do crente era o de vir 